\title{
O MITO DE PROMETEU E O CANTO LIBERTÁRIO DE CASTRO ALVES
}

\section{Enaura Quixabeira Rosa e Silva (UFAL)}

Sublime no sofrer, vencido, - não domado, Na sublime agonia arqueja Prometeu.

Povo! Povo infeliz! Povo, mártir eterno. Tu és do cativeiro o Prometeu moderno... Castro Alves, Obras completas, p. 529-530.

Prometeu nasce personagem da mitologia grega como o titã criador da raça humana que amassara em argila e água ou, talvez, com suas lágrimas. Enquanto reinou Crono, homens e deuses foram iguais. Quando Zeus oprime os homens, impondo-lhes a supremacia divina, Prometeu rouba para eles o fogo e lhes ensina várias artes, que lhes permitiriam o acesso ao conhecimento. Como punição, Zeus imagina perder os homens por meio de uma mulher, dotada de todos os encantos, mas, também, da mentira e da astúcia. Pandora-aquela que possui todo os dons - trouxe consigo um jarro do qual sairam todos os males que, desde então, afligem a humanidade; no fundo do jarro ficou apenas a esperança para suavizar a condição humana. Zeus executa contra Prometeu um terrivel castigo: acorrenta-o a um rochedo inacessível onde uma águia roía-lhe o figado durante o dia. Para desespero do titã, o órgão se recompunha à noite, recomeçando o suplicio assim que o sol surgia no horizonte. Essa tortura prolongou-se por tempos imemoriais. Eis em rápidas pinceladas, o "mito canonico de Prometeu" na concepção de Hesíodo'. Na narração hesíodica,

Hesíodo oferece do mito duas versões complementares. Na Teogonia (v. 507-616), ele relata que para acabar com uma querela entre os deuses e os homens, era necessário que se oferecesse um sacrificio a Zeus. Prometeu. fillho do titã Jápeto e da oceânida Climene, decide enganar Zeus. Divide um bol em duas partes, cobrindo com a pele do animal os bons pedaços de carne e colocando os ossos sob uma camada de gordura apetitosa. Em 
Prometeu causa a desgraça dos homens, cujo destino se concebe, então, em termos de queda e decadência, sem nenhuma apologia da revolta: a lição de Hesíodo é a submissão à vontade divina.

Assim é o mito, forma viva que nasce do diálogo do homem com a natureza, viceja, e nem sempre morre porque aproveitada e fixada pelos poetas. Se o mito está na origem da poesia, está, por isso mesmo, na origem da literatura. O mito de Prometeu ressurge enriquecido e transfigurado a partir do momento em que Ésquilo coloca-o em cena, na tragédia Prometeu acorrentado (entre 467 e 459 a. C.). O mitologema é apresentado de modo mais amplo e poético. Porque Zeus pretende, por capricho, exterminar a humanidade, o Prometeu esquiliano rouba o fogo à divindade, oferta-o aos homens, iniciando-os, desse modo, nas artes e nas técnicas. Vítima da tirania e da ingratidão de Zeus, que ele ajudara a apoderar-se do poder, o titã transforma-se em herói. deixando-se acorrentar em um dos picos mals elevados do Cáucaso, sob a vigilância do Poder e da Força. Apesar de seus sofrimentos, Prometeu recusa humilhar-se diante do tirano. rejeita a intercessão do Oceano, e, sozinho, grita sua indignação à terra e aos céus, resistindo até o fim.

Numa considerável ampliação do mito, Ésquilo define uma nova concepção da condição humana que, graças às boas obras de Prometeu, é agora apresentada em termos de progresso e não mais, como em Hesíodo, numa perspectiva de decadência e nostalgia da idade do ouro (Trousson apud Brunel, 1997, p. 786).

Segundo Kitto, Ésquilo apropria-se das concepções primitivas para dar sustentação ao seu conceito de mito, em particular, como "a concepção sombria de uma Necessidade ainda mais forte que os deuses": a necessidade de não se submeter a nenhuma tirania (1972, p.

represália, Zeus nega entregar o fogo aos homens, protegidos do titã Prometeu rouba o fogo, entregando-o aos homens. Isso the valera uma dupla punição: Hefesto esculpe uma estátua de mulher e envia aos homens esse "belo flagelo", enquanto Prometeu acorrentado a uma columa vé seu figado devorado por uma águia renascer perpetuamente. Em $O$. trabalhos e os dias (v. 42-105), poema moralista e didático, Hesiodo fornece dados suplementares. A criatura feminina agraciada com a arte de seduzir e dissimular chama-se Pandora e traz consigo todas as desgraças que atormentam a humanidade. O relato de Hesiodo tem uma funçào etiológica: explicar a miséria da condição humana e ensinar o respeito aos deuses. Cf. Pierre Brunel, Dicioncirio de mitos literirios 1997, p. 785. 
111). Trousson discorda dessa posição ao afirmar que "ao conceder inteligência e livre-arbitrio aos homens, o Prometeu de Ésquilo não lhes ensina a revolta contra os deuses, mas faz com que ela se torne possivel" (Ibid., p. 787). É essa possibilidade inscrita nas entrelinhas que vai seduzir os modernos.

Do século IV ao V, Prometeu atravessa longo período de luz e sombra, quando suas aparições se fazem raras. O mito transmite-se quase exclusivamente pelas obras latinas e a versão de Ésquilo permanece ignorada. O Ocidente cortara seus canais de comunicação com a cultura grega.

Ausente das obras profanas, ele pode ser encontrado nos textos dos escritores cristãos e dos Padres de Igreja, alimentando a controvérsia entre paganismo e cristianismo, reduzido, entretanto, a um personagem ilustre da Antigüidade Grega, abusivamente divinizado por um povo ignorante, na visão de Clemente de Alexandria ou Eusébio de Cesaréia. Autor da frase famosa "O verdadeiro Prometeu é o Deus Todo-Poderoso dilacerado pelos suplícios", Tertuliano e também Santo Agostinho adotaram Prometeu, crucificado e revoltado contra os "falsos deuses", como uma prefiguração do Cristo redentor, "o verdadeiro Prometeu". Mas, a cristianização do mito apenas ocorre antes do século XVI (Trousson apud Brunel, p. 787). A partir do Renascimento, ao contrário, Prometeu passa a ser visto como um simbolo da consciência humana erigida contra toda forma de arbitrariedade.

O romantismo confere-lhe popularidade ao exaltar-lhe o orgulho humano revoltado contra a divindade. Confiante em seu gênio criador, o Prometeu rómântico desafia, de igual a igual, e mesmo com uma piedade desdenhosa, este Zeus ao qual ele nada deve. O gigante orgulhoso de sua força física é o homem de ação, simbolizando o mundo real, útil, prático em oposição a Epimeteu, seu irmão, o contemplativo. Byron evoca - em dois poemas, Ode a Napoleão Bonaparte (1814) e Prometeu (1816) - a constância e a firmeza de alma do titã, símbolo do gênio incompreendido.

Para Trousson, a grande obra romântica é o Prometeu Libertado (1820), drama lírico, em cinco atos, de Shelley. Na óptica desse autor, Prometeu configura a humanidade, que, por suas próprias fraquezas, deu origem ao mal, mal metafísico, é verdade. mas também, um mal em todas as suas formas religiosas, sociais e 
políticas, metaforizado no deus Júpiter. Prometeu-Humanidade, ajudado por Ione (a Esperança) e Pantéia (a Fé no homem) triunfa sobre o mal - graças à intervenção de Demogórgon (a Fiorça das coisas suscitada pela purificação interior), instaurando a lei do amor universal. Distanciado dos deuses inúteis, o Prometeu de Shelley confia numa humanidade capaz de por si mesma abrir caminho na direção do bem e da justiça (Ibid. p. 791-2).

Historicamente, nesse periodo, a arte européia rompe com o pensar clássico, naquilo que ele possuía de prescritivo, e começa a articular-se de forma autònoma. Victor Hugo afirma a beleza existente nos personagens dos meios populares e consagra a estética do grotesco. Falbel coloca que o período romântico, fruto de dois grandes acontecimentos na história da humanidade - a Revolução Francesa c a Revolução Industrial -, é agitado por profundas transformaçòes sociais e econômicas, pelo surgimento de novas ideologias e tconas acerca do Estado, pela ampliação do campo cientifico e irrupção do nacionalismo. Graves problemas de ordem social eclodem en relaçiu às massas de trabalhadores, base humana na qual se apoiava essia mudança sofrida pela sociedade européia $(1985$, p. 24 ss). A estétrca romantica institui-se, assim, como espaço de formação de nacionalidade enquanto busca de uma identidade étnico-cultural c construção de uma historicidade especifica.

É nesse ideário do romantismo que desejamos situar o mito de Prometeu na literatura brasileira. Estamos na segunda metade do século XIX. Um jovem poeta baiano António Frederico de Castro Alves trabalha o texto poético como descoberta e profecia. Descobre it situação do homem, etnicamente discriminado, reduzido à escravidão mais vil, a serviço do enriquecimento de uma classe privilegiada. I sua voz ergue-se como clamor retumbante nas Vozes d'Africi. tentando acordar "o gigante adormecido".

Contudo, sua inteligência arguta e jovem percebe que há outras formas de servidão que acorrentam o homem independente de etnias. Não é apenas a cor da pele que escraviza, mas a "aristocracia" oligárquica - do nome de familia, do prestigio político e do poderio economico que expulsa o homem do processo social.

A abolição da escravatura impõe-se como urgente e necessária, todavia, o povo precisa de uma alforria mais abrangente, precisa de subtrair-se ao jugo feroz de um império arcaizante, precisa 
do estatuto da cidadania que só "a alforria republicana" pode conceder. Isso exige um mergulho nas raízes históricas para encontrar no passado um sentido para o presente.

Castro Alves vai, então, ao passado mitológico e traz Prometeu; mergulha nos espaços da lição histórica nacional e recupera Pedro Ivo. Dois poemas, duas falas libertárias: Pedro Ivo (1865) poema épico - estruturado em cinco cantos e Prometeu (1868).

Em Pedro Ivo, no Canto I, delineia-se a paisagem aterradora da tirania: "noite de horrores". A natureza participa, criando o cenário da borrasca em que o vento geme e as árvores se retorcem e tremem.

Rebramam os ventos... Da negra tormenta Nos montes de nuvens galopa o corcel...

É noite de horrores... nas grumas celestes,

Nas naves etéreas o vento gemeu...

E os astros fugiram, qual bando de garças

Das águas revoltas do lago do céu.

E a terra é medonha... As árvores nuas

Espectros semelham fincados de pé,

Com os braços de múmias, que os ventos retorcem,

Tremendo a esse grito, que estranho lhes é.

(Canto I, estrofes 1, 2 e 3)

Da bruma do tempo, emerge a figura de um cavaleiro solitário que estabelece com a cidade um diálogo que se estende no II e III cantos. Pedro Ivo, o herói que a cidade expulsou, denuncia a escravidão, a corrupção, os desmandos que habitam a cidade, antes "vestal da pureza", hoje, "prostituta em negra órgia" (sic), "louca" que enterrou sua dignidade a serviço do poder - "riso de Satanás". O passado de glórias e feitos heróicos está morto. Por que está morto"? Qual seria a causa? O regime monárquico e sua tirania. 
Responde o espectro: “A desgraça!

Que a realeza, que passa,

Com o sangue de vossa raça,

Cospe lodo sobre vós!..."

(Canto II, estrofe 5)

O herói banido diz a que vem. É um guerreiro à semelhança de Napoleão. Exilado, prepara-se para novas batalhas. Seu alvo? A autoridade real investida de poder.

Recuo de uma passada,

P'ra levar de derribada

Rochedos, reis, multidão...!

(Canto II, estrofe 8)

No Canto III, ele identifica a cidade, localizando-a na Província de Pernambuco. Esculpe em palavras e pedra - "recife imenso" - a personificação do passado glorioso e revolucionário, cujos ideais libertários metaforizam-se nos líderes da Revolução Francesa - Robespierre, Danton e Mirabeau -, detentores de posições mais radicais. Contudo, proclama uma certa irmandade com Vergniaud $^{2}$, representante das tendências mais moderadas. caracterizando o espaço democrático republicano.
"Pernambuco! Um dia eu vi-te
Dormido imenso ao luar,
Com os olhos quase cerrados,
Com os lábios - quase a falar...
Do braço o clarim suspenso.
- O punho no sabre extenso
De pedra - recife imenso,
Que rasga o peito do mar...

Pierre Vergniaud (1753-1793). politico francés (deputado girondino) que

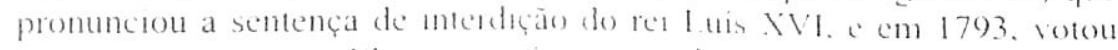
stat morte sem sursis f.ke mesmo fin executade em junho de 1793. 
E cu disse: Silêncio, ventos!

Cala a boca, furacão!

No sonho daquele sono

Perpassa a Revolução!

Esse olhar que não se move

'Stá fito em Oitenta e Nove -

Lê Homero escuta Jove...

- Robespierre - Dantão.

Naquele crânio entra em ondas

$\mathrm{O}$ verbo de Mirabeau...

Enquanto em su'alma brada:

"Somos irmãos, Vergniaud."

(Canto III. estrofes 1, 2 e 3 )

Na estrofe 4 do mesmo Canto, a voz de Pedro Ivo conclama o povo - herói real - a tomar consciência de seu papel. É da mitologia, sonho coletivo de todos os povos e de todos os homens, que o poeta retira as imagens de seu canto libertário: Sansão - juiz bíblico simbolo da força, da revolta da justiça e Prometeu - investido de rebeldia e resistência.

Então repeti ao povo:

- Desperta do sono teu!

Sansão - derroca as colunas!

Quebra os ferros - Prometeu!

O povo - Prometeu/cidadão - precisa libertar-se a fim de poder realizar o sonho da liberdade: "República!... Vôo ousado/ do homem feito condor!/" (Canto III, estrofe 5). Mas, quem é esse que se arvora do direito de líder do povo? É o capitão Pedro Ivo, figura heróica da Revolução Praieira. Amaro Quintas aproxima os feitos do Capitão da Praia às ações dos partisans e do maquis da última guerra mundial (1977, p. 84). Pedro Ivo representa, principalmente, o herói 
popular que se embrenha no interior, organiza e sustenta a resistência nas matas de Água-Preta, no vale do Jacuípe. No comando de um grupo de camponeses maltrapilhos e despreparados para enfrentar a topografia de uma cidade com a qual não estavam familiarizados, luta no interior, atacando e recuando, e se transforma numa lenda nordestina ${ }^{3}$. Preso em Alagoas, em 1850, encarcerado na Fortaleza da Laje, no Rio de Janeiro, escapa da prisão, embarca para a Europa, mas falece em plena viagem, em 1851. Pedro Ivo:

As estrofes seguintes descrevem, poeticamente, a luta de

Inda me lembro... Era, há pouco.

A luta!... Horror!... Confusão!...

A morte voa rugindo

Da garganta do canhão!...

Foi uma luta de bravos,

Como a luta do jaguar,

De sangue enrubesce a terra,

- De fogo enrubesce o ar!...

... Oh!... mas quem faz que eu não vença?

Não importa! A liberdade

É como a hidra, o Anteu,

Se no chão rola sem forças,

I:m 7 de abril de 1831, D. Pedro I abdicou do trono brasileiro em favor de D. Pedro de Alcântara, seu filho mais novo. A partir dai até 23 de julho de 1840. quando foi declarada a maioridade (aos 15 anos) do principe, agora, Sua Majestade Imperial, D. Pedro II, decorreu um periodo histórico conhecido como Regência (Provisória e Permanente), marcado por uma forte agitação política e social. Durante o Segundo Reinado muitas foram as revoluçōes militares ou de cunho popular: Cabanagem, a Guerra dos Farrapos, a Balaiada, as revoltas liberais de Minas Gerais e São Paulo e a Revolução Praieira (1848-1851). Esse movimento foi a última das revoltas ocorridas no reinado de Pedro II, sendo seus principais lideres Joaquim Nunes Machado, Antonio Borges da Fonseca, José Inácio de Abreu Lima e Pedro Ivo; seus seguidores, en geral, eram trabalhadores rurais. Cf. Herculano Gomes Mathias (coord.) et al. História do Brasil, v. II, 1972. 
Mais forte do chão se ergueu...

São os seus ossos sangrentos

Gládios terríveis. sedentos...

E da cinza solta aos ventos

Mais um Graco apareceu!...

(Canto III, estrofe 6, 8 e 9)

No texto poético, a imagem da liberdade constrói-se a partir das figuras da hidra de Lerna e do gigante Anteu, como algo que renasce a partir da destruição. A hidra, dragão com corpo de réptil. possuía nove cabeças. A cada cabeça cortada, onde houvera uma, renasciam duas. Anteu, filho de Posidon e Géia, tinha o privilégio de retomar as forças perdidas sempre que seus pés tocavam a mãe Terra.

A referência aos irmãos Gracos, Tibério e Caio (162 e 154 a.C.) é interessante, se considerarmos que ambos lutaram pela pequena propriedade, na Roma antiga, limitando os avanços dos grandes proprietários sobre as terras do ager publicus. Suas propostas de lei agrária encontram a hostilidade da nobreza, o que os levou ao caminho da ilegalidade e à morte durante sublevações.

Ainda no Canto III, a voz do herói relembra o exílio em um prelúdio de morte. Ele não verá o dia em que "o povo acordado" irá concretizar seus ideais.

"Adeus! Vou por ti maldito

Vagar nos ermos pauis

Tu ficas morta, na sombra,

Sem vida, sem fé, sem luz!...

Mas quando o povo acordado

Te erguer do tredo valado,

Virá livre, grande, ousado,

De pranto banhar-me a cruz!..."

(estrofe 11)

Silencia-se a voz de Pedro Ivo, no Canto IV. Ouve-se, então, a $10 \%$ do poeta a indicar o espaço do sertão como espaço da liberdade: "Lá não vão os vermes perseguir as águias./ Não vão escravos perseguir 
a ti!" (estrofe 4). Nas duas últimas estrofes desse mesmo Canto, o poeta descreve a indumentária do herói - dominado -, diferençando-a da roupa do dominador, conferindo-lhe uma dignidade universal:

Vai!... Que teu manto de mil balas roto

É uma bandeira, que não tem rival.

Vai, tu que vestes do bandido as roupas,

Mas não te cobres de uma vil libré

Se te renega teu pais ingrato

O mundo, a glória tua pátria é!...

O Canto $\mathrm{V}$ mitifica o herói nas duas primeiras estrofes, reservando-lhe um lugar de marginalizado da história oficial:

...Mas contam que um dia rolara o oceano

Seu corpo na praia, que a vida lhe deu...

Enquanto que a glória rolava sua alma

Nas margens da história, na areia do céu!...

A outra fala libertária de Castro Alves é um poema composto de três estrofes que se intitula Prometeu. As duas primeiras estrofes descrevem a agonia do titã em seu castigo, mas conserva a exemplo de Esquilo, "traços de resistência", tendo como consolo o pranto das Nereidas:

Inda arrogante e forte, o olhar no sol cravado,

Sublime no sofrer, vencido, - não domado,

Na sublime agonia arqueja Prometeu.

() Cáucaso é seu cepo; é seu sudário - o céu,

Como um braço de algoz, que $\mathrm{em}$ sangueira se nutre, Revolve-lhe as entranhas o pescoço do abutre.

Vós, Nereidas gentis, meigas filhas do mar!

O oceano the trazei, p'ra em prantos derramar... 
Na estrofe seguinte, Prometeu transforma-se na "alegoria do povo". tendo como algoz a tirania dos "maus reis" e suas leis injustas, e como instrumento de tortura - o poder. Nacionaliza-se o mito, transferindo-o de espaço. Prometeu agoniza, agora, no continente sulamericano: "Era pequeno o Cáucaso... amarram-te nos Andes."

Nos versos a seguir, percebe-se uma questão bem peculiar dos fundamentos filosóficos do Romantismo enquanto fenômeno histórico: "E enquanto, tu, titã, sangrento arcas aí,/ O século da luz olha... caminha... ri..."

Para Jacó Guinsburg, o Romantismo é "uma forma de pensar que pensou e se pensou historicamente". Durante o século XVIII, "século do Iluminismo". o pensamento dominante é aquele que considera a História como produto do rei-filósofo, do déspota esclarecido, das "vidas-ilustres" que iluminam e melhoram o homem. produzindo o progresso em suas instituições, pela razão e ação. $\mathrm{O}$ Romantismo subverte essa maneira de pensar, centrando suas fontes propulsoras não na ação isolada do homem abstrato, singularizado pela razão, mas no gênio intuitivo investido de uma missão, que é o herói romântico, encarnação de uma vontade mais social que pessoal (1985, p. 14-16).

É a serviço do povo - Prometeu moderno - que o poeta oferece sua voz enquanto discurso apocalíptico e profético, como espaço público para discussão dos destinos da humanidade.

A musa do poeta irá - filha do mar -

O oceano de sua alma... em cantos derramar... 


\section{REFERÊNCIAS BIBLIOGRÁFICAS}

ALVES. Castro. Poesias completas. Introdução de Jamil A. Haddad. Org., rev. e notas de Frederico José da S. Ramos. São Paulo: Saraiva, 1953.

ALVES, Castro. Espumas flutuantes. Introdução e notas de Vicente Ataide. Curitiba: HD Livros, 1997. (Coleção Clássicos Brasileiros (comentados).

AI.VES, Castro. Espumas flutuantes. Poemas. Notas de Frederico Barbosa e Sylmara Beletti. Indiana: Klick Editora, 1997 (Biblioteca O Estado de São Paulo Jornal)

ATAIDE, Vicente. Introdução. In: Espumas flutuantes. Curitiba: HD Livros, 1997. (Coleção Clássicos Brasileiros Comentados)

BORNHEIM, Gerd A. Aspectos filosóficos do romantismo. Porto Alegre: Secret. da Educação/Instituto Estadual do Livro, 1959. (Cadernos do Rio Grande VIII)

BRANDÃO, Junito de Souza. Dicionário mítico-etimológico da mitologia gregat. Vol II. Petrópolis: Vozes, 1991.

BRUNEL, Pierre (org.). Dicionário de mitos literários. Trad. de Carlos Sussekind et alii. Prefácio de Nicolau Sevcenko. Rio de Janeiro: José Olympio, 1997.

l:ALBEL, Nachman. Os fundamentos históricos do romantismo. In: (jUINSBURG, J. (org). O Romantismo. 2. ed. São Paulo: Perspectiva, 1985. (Coleção Stylus)

GRIMAL, Pierre Dicionario de mitologia. Griega y romana. Prefäcio de Charles Picard. Prólogo de Pedro Pericay. Barcelona: Ediciones Paidós, [s.d.].

(jUIMARÃES, Ruth. Dicionário da mitologia grega. São Paulo: ('ultrix, 1995.

(jlinsbURG, Jacó. O Romantismo. 2. ed. São Paulo: Perspectiva. 1985. (Coleção Stylus). Romantismo, historicismo e história.

IIISSIODO. Teogonia. São Paulo: Iluminuras, [s.d.]. 
KITTO, H. D. F. A tragédia grega, Estudo literário. Vol. 1. Trad. e prefácio de José Manuel Coutinho e Castro. Coimbra: Arménio Amado, 1972. (Coleção Studium; 91)

KURY, Mário da Gama. Dicionário de mitologia grega e romana. 3. ed. Rio de Janeiro: Zahar, 1994.

LAFFONT-BOMPIANI. Dictionnaire des personnages. Littéraires et dramatiques de tous les temps et tous les pays. Collection Bouquins, Éditions Robert Laffont, 1992.

MATHIAS, H. G. (coord.) et. al. História do Brasil. v. II Rio de Janeiro: Bloch Editores, 1972.

QUINTAS, Amaro. O sentido social da Revolução Praieira. 5. ed. Recife: UFPE/ Edit. Univ., 1977.

VERNANT, Jean-Pierre. Mito e pensamento entre os gregos: estudos de psicologia histórica. Trad. de Haiganuch Sarian. Rio de Janeiro: Paz e Terra, 1990.

VICTORIA, Luiz A. P. Dicionário ilustrado da mitologia. Rio de Janeiro: Ediouro, [s.d.]. 